\title{
Ceftizoxime in the treatment of uncomplicated gonorrhoea
}

\author{
ROBERT C SPENCER,* TERENCE SMITH,* AND MARTIN D TALBOT† \\ From the Departments of ${ }^{*}$ Bacteriology and + Genitourinary Medicine, Royal Hallamshire Hospital, \\ Sheffield
}

SUMMARY A total of 74 men and 26 women with uncomplicated gonorrhoea were treated with ceftizoxime sodium $0.5 \mathrm{~g}$ intramuscularly. The cure rate was $99 \%$ and included successful treatment of four infections due to $\beta$-lactamase producing organisms. The minimum inhibitory concentrations (MICs) of ceftizoxime in vitro were very much lower than those of penicillin and cefuroxime, and side effects were minimal. We conclude that ceftizoxime is effective against Neisseria gonorrhoeae in vivo and in vitro.

\section{Introduction}

Ceftizoxime is a new semisynthetic parenteral cephalosporin which is stable against most $\beta$-lactamases. It has high peak serum concentrations after injection, low protein binding, and is excreted unchanged in the urine. The serum half life is 100 minutes. These properties make ceftizoxime a potentially useful antibiotic for the treatment of genital infections due to Neisseria gonorrhoeae. We therefore examined the efficacy of a single $0.5 \mathrm{~g}$ dose of ceftizoxime in the treatment of uncomplicated gonorrhoea.

\section{Patients and methods}

\section{PATIENTS}

We studied 115 consecutive patients presenting to the department of genitourinary medicine with culture positive uncomplicated anogenital gonorrhoea. Samples were taken from the urethra of heterosexual men and from urethra, rectum, and pharynx of homosexual men. Samples were taken from the urethra, cervix, rectum, and pharynx of women who were known contacts. Other women who subsequently gave positive results for $N$ gonorrhoeae also had samples taken additionally from the rectum and pharynx on at least two follow up occasions. Patients were treated with a single dose of ceftizoxime sodium $0.5 \mathrm{~g}$ given intramuscularly, and were seen for follow up at an average of 3 days after treatment (range 2-6 days) when repeated samples were taken for culture.

Address for reprints: Dr M D Talbot, Department of Genitourinary Medicine, Royal Hallamshire Hospital, Glossop Road, Sheffield S10 2JF

Accepted for publication 13 September 1983

\section{BACTERIOLOGICAL METHODS}

All samples were inoculated immediately on to gonococcal medium, composed of Difco GC agar base, $10 \%$ lysed horse blood, $1 \%$ sterile defined supplement (Kellogg's modified formula), and Oxoid antibiotic supplement, and were incubated in an atmosphere containing $8 \%$ carbon dioxide. $N$ gonorrhoeae was identified by using the Minitek identification procedure (BBL Microbiology Systems) and tested for the production of $\beta$-lactamase by the chromogenic cephalosporin technique. Agar dilution susceptibility testing was performed for ceftizoxime, cefuroxime, and penicillin using an inoculum of $5 \times 10^{5}$ colony forming units (cfu) $/ \mathrm{ml}$ on the gonococcal medium without the antibiotic supplement. The minimum inhibitory concentration (MIC) was the lowest concentration of antibiotic that inhibited the growth of clinical isolate after appropriate incubation for 24 hours.

\section{Results}

Of 115 patients enrolled in the trial, 15 defaulted from follow up. The distribution of infection sites is shown in table I. The only treatment failure was in a woman with continuing urethral and cervical infection five days after treatment, and this may have repre-

TABLE I Distribution of sites infected with $N$ gonorrhoeae in 100 patients

\begin{tabular}{lllll}
\hline Patients & Urethra & Cervix & Rectum & Pharynx \\
\hline Men $(\mathrm{n}=74)$ & 69 & & 8 & \\
Women $(\mathrm{n}=26)$ & 24 & 24 & 12 & 2 \\
Total $(\mathrm{n}=100)$ & 93 & 24 & 20 & 2 \\
\hline
\end{tabular}


TABLE II Percentages of 100 clinical isolates of $N$ gonorrhoeae inhibited by different concentrations of three antibiotics

\begin{tabular}{|c|c|c|c|c|c|c|c|c|c|c|}
\hline \multirow[b]{2}{*}{ Antibiotic } & \multicolumn{10}{|c|}{ \% Inhibited by concentrations ( $\mathrm{mg} / \mathrm{l}$ ) of: } \\
\hline & $\leqslant 0.007$ & 0.015 & 0.03 & 0.06 & $0 \cdot 125$ & 0.25 & 0.5 & 1 & 2 & $\geqslant 4$ \\
\hline $\begin{array}{l}\text { Ceftizoxime } \\
\text { Cefuroxime } \\
\text { Penicillin G }\end{array}$ & $\begin{array}{r}100 \\
28 \\
6\end{array}$ & $\begin{array}{l}64 \\
26\end{array}$ & $\begin{array}{l}73 \\
30\end{array}$ & $\begin{array}{l}87 \\
51\end{array}$ & $\begin{array}{l}91 \\
65\end{array}$ & $\begin{array}{l}95 \\
79\end{array}$ & $\begin{array}{l}99 \\
89\end{array}$ & $\begin{array}{l}100 \\
94\end{array}$ & 98 & 100 \\
\hline
\end{tabular}

sented reinfection rather than a failure of treatment, as the organism was fully sensitive to ceftizoxime. The cure rate was therefore 99 out of $100(99 \%)$. There were no significant side effects, but most patients experienced pain at the site of the injection.

Table II shows the MICs of penicillin, cefuroxime, and ceftizoxime; concentrations of $\geqslant 4 \mathrm{mg} / \mathrm{l}, 1 \mathrm{mg} / \mathrm{l}$, and $\leqslant 0.007 \mathrm{mg} / \mathrm{l}$ respectively resulted in $100 \%$ inhibition of the organisms isolated.

\section{Discussion}

We found $0.5 \mathrm{~g}$ of ceftizoxime effective in the treatment of gonorrhoea, which confirmed the findings of Slutkin et al and Lutz et al. ${ }^{2}$ Our isolates demonstrated considerable sensitivity to ceftizoxime, which had an MIC of $<0.007 \mathrm{mg} / \mathrm{l}$ for all isolates. These figures are lower than previously reported. ${ }^{12}$

It is worth noting that infections at all sites including the rectum and pharynx were readily cured by $0.5 \mathrm{~g}$ ceftizoxime, despite the belief that rectal and pharyngeal infections are more difficult to cure than those at other sites. ${ }^{3}$ Ceftizoxime was also effective against $\beta$-lactamase producing organisms. We feel that this broad spectrum cephalosporin antibiotic has a place in the treatment of infection caused by penicillinase producing $N$ gonorrhoeae (PPNG) and non-PPNG. Further work in rectal and pharyngeal infections would be helpful.

We thank the Wellcome Foundation who supplied the ceftizoxime, the staff of the department of genitourinary medicine who assisted with patient management, and Dr G R Kinghorn who gave valuable advice.

\section{References}

1. Slutkin G, Gottlieb A, Mills J. Ceftizoxime for treatment of gonorrhoea. J Antimicrob Chemother 1982; 10suppl:237-9.

2. Lutz B, Mogabdab WJ, Parks D, Pauling B, Reville R. Comparison of ceftizoxime and penicillin for the treatment of uncomplicated gonorrhoea. J Antimicrob Chemother 1982; 10suppl:229-35.

3. Morton RS. Gonorrhoea. London: WB Saunders, 1977. 